\title{
Research on the Cultivation of Practical Innovative Ability of Applied Electronic Information Talents
}

\author{
Fen Liu \\ School of Electronic Engineering, Tianjin University of Technology Education \\ Tianjin, 300222
}

\begin{abstract}
Compared with the academic type, practical innovation ability is more important for the cultivation of applied talents. At present, the cultivation of practical and innovative ability of electronic and information applied talents cannot fully meet the needs of social and economic development. Therefore, this paper analyzes the deficiencies of cultivating the practical innovative ability of electronic and information professionals, and puts forward some concrete solutions. According to the needs of society and enterprises for the practical ability of electronic and information applied talents, the training system of practical and innovative ability is constructed from the three dimensions of theory, practice and innovation.
\end{abstract}

Keywords-Practical innovative ability; Applied talents; Cultivation system; Quality guarantee

\section{INTRODUCTION}

The Higher Education Law of the People's Republic of China stipulates that the task of higher education is to train senior specialized personnel with social responsibility, innovative spirit and practical ability, develop science, technology and culture, and promote socialist modernization. Electronic information specialty is a very strong application of professional, is to train in the field of electronic information in research and management of advanced engineering and technical personnel. Therefore, the cultivation and teaching of electronic information students not only require students to master the solid theoretical basis of this major, but also must have a strong practical ability and innovation ability.

\section{INSUFFICIENCY OF PRACTICAL AND INNOVATIVE EDUCATION FOR ELECTRONIC INFORMATION SPECIALTY}

(1)The concept of practice innovation is backward. Traditional education is a kind of inheritance education centered on imparting knowledge [1]. It does not attach enough importance to practical courses to cultivate students' practical and innovative ability, which makes practical courses often fail to achieve the desired results. Therefore, we must change the concept of practical innovation education, mainly including the following aspects: the practical purpose from verification and assessment to research and innovation, the evaluation mechanism from machine hours to the utilization of resources, the practice mode from a stand-alone experiment to a systematic experiment, to enhance students' subjective consciousness and practical motivation.
(2)Practice innovative teaching system and content are unreasonable [2]. The design of practical innovation teaching system and content will directly affect the teaching effect of the course and the quality of personnel training. The traditional practice innovation teaching system is in a closed state, lack of connection between the front and back courses, less use of cross-disciplinary knowledge, hinder the improvement of students' ability to solve problems systematically, and is not conducive to the cultivation of students' innovative thinking and practical ability. In addition, practice teaching is often confined to the classroom, and there is less teaching outside the classroom. In the aspect of practical teaching content, the experimental contents of basic verification type are too much, and the experimental contents of comprehensive design type and research innovation type are too few. This is seriously out of touch with the new theory and new technology of electronic information.

(3)Practice innovation teaching mode and assessment method is single. In traditional practice teaching, in order to realize the practice report, students often lack the time and space to think independently in the process of practice, which leads to the lack of analysis and practice ability, and restricts the development of students' practical innovation ability. In terms of assessment methods, most of the students are assessed on the basis of practical operation and practice reports. But this kind of assessment method is difficult to achieve objective and fair, and easy to lead to the phenomenon of plagiarism, is not conducive to the cultivation of students' independent learning ability and innovative spirit.

\section{CONSTRUCTING THREE DimENSIONAL TRAINING SYSTEMS FOR PRACTICAL INNOVATION ABILITY}

The cultivation of practical innovation ability is embodied in three dimensions: theory, practice and innovation. The intersection of the three dimensions is the practical innovation ability of the students. Therefore, in order to improve students' practical and innovative ability, we must construct a scientific theoretical curriculum system, practical system and quality education system. 
A. Constructing a theoretical curriculum system to meet the needs of electronic information enterprises based on "consolidating the foundation and focusing on development".

The theoretical curriculum system consists of two modules: core knowledge and cutting-edge technology [3]. The core knowledge module, which is composed of eight core courses, is determined according to the Catalogue of Undergraduate Specialty and Professional Introduction of Colleges and Universities stipulated by the Department of Higher Education of the Ministry of Education. The frontier technology curriculum module is constructed by school-enterprise cooperation. Its purpose is to enable students to timely understand the latest developments in disciplines and majors and master the mainstream technology in the industry. In the process of construction, we can adopt such methods as replacement, renewal and creation, that is, replacing the credit course in the school teaching plan with the enterprise training course, updating the course contents or creating new courses in time according to the latest technology trends, industry needs and project development information from the industry.

\section{B. Constructing a progressive practice teaching system based on comprehensive project practice}

According to the requirements of electronic information enterprises for students' practical and innovative ability, the practical teaching system is constructed from four aspects: content, process, method and examination. In terms of teaching content, the project practice has changed from single and verifying experiment to basic verifying, comprehensive designing and innovative research. In the teaching process, the process of organizing by chapters and knowledge points is transformed into a progressive practical teaching process with task-driven as the main line [4]. In the teaching method, the traditional teaching method based on demonstration and imitation is changed to the interactive and practical teaching method. In the teaching examination, we should change the written examination from the centralized examination knowledge to the gradual examination method which runs through the whole teaching process and focuses on cultivating students' ability.

\section{Constructing a quality education system with stages and steps}

In the stage of freshman entrance education, we should integrate vocational quality education, introduce the post requirements of electronic information industry, and guide students to make clear direction, correct orientation and dislocation competition for their own development. In the basic and professional learning stage, organize students to visit relevant enterprises to understand their culture, development status and capacity needs. Help students to further clarify their future development goals, stimulate their enthusiasm for learning and their own potential for development, and strengthen the sense of teamwork. At the graduation stage, invite enterprises to come to schools for graduate recruitment talks. Through the cooperation mode of study, training and employment, the achievement of quality education can be realized to improve the employment rate of students.

\section{IMPROVING PRACTICE TEACHING Mode AND MethoD}

\section{A. Establishing a practical teaching mode of school enterprise cooperation}

In order to achieve the goal of training applied talents with strong practical and innovative ability for local electronic information enterprises, the teaching mode of " $2.5+1.5$ " can be implemented by relying on two teaching teams of full-time teachers and part-time teachers of enterprises. During the twoand-a-half years of the first, sophomore and junior semester, full-time teachers mainly complete the teaching of public basic courses, professional basic courses and professional core courses, so as to cultivate students' innovative consciousness and practical ability [5]. During the one and a half years from the beginning of the second semester of junior year, part-time teachers from enterprises come to school to offer professional training courses, carry out course replacement, arrange students to practice in enterprises and carry out graduation projects. In the process of graduation project, the dual-teacher system of school teachers and enterprise technicians is implemented. As a member of enterprise project team, students can understand the project deeply and improve their practical ability.

\section{B. Promoting the reform of practice teaching organization and method}

According to the development trend of the subject and the basic requirements of cultivating innovative talents, the teaching should be organized according to the thinking of "basic verification type, comprehensive design type, and research innovation type". In the course of teaching, first of all, students can consolidate the theoretical knowledge they have learnt and cultivate their preliminary practical ability by means of basic verifying practice. Then, students can be guided to think in an all-round way and solve problems by using knowledge comprehensively through comprehensive designing practice. Finally, we should cultivate students' scientific research spirit and innovation ability by studying innovative practice.

Prompt teaching can be adopted in the basic verification practice teaching. During the inspection tour, teachers asked questions in a way of "knowing what they ask". By designing the problem situation, the teacher lets the students answer and solve the problem, and analyzes the rationality and feasibility of the students' solution. Through this teaching mode, students' initiative can be effectively stimulated, and students' understanding of practical principles and programs can be greatly deepened.

Because students have a certain basis for practical training, so in the comprehensive design-based practice and research innovation-based practice teaching, teachers and students can participate in the inquiry teaching model. Before the beginning of the practice teaching, the teacher put forward tasks for each group in advance. On the basis of autonomous learning, students choose the core part of the project to discuss and give full play to the interactive and complementary functions of group learning subjects. At the same time, communication debates between groups and groups are conducted to foster students' collective consciousness and competition consciousness. Through this teaching method, students' interest 
in learning, autonomous learning and multi-directional communication ability, collective consciousness and competitive consciousness can be greatly enhanced and enhanced.

\section{CREATE DiVERSIFIED PlatForms For PRACTICE AND INNOVATION}

The cultivation of practical innovation ability is inseparable from the construction of practical innovation platform, which is the carrier and grasp of cultivating students' practical innovation ability. Practice and innovation platforms for electronic and information majors mainly include: course experiment platform (in-course experiment, independent experiment course), course design platform (cross-course design comprehensive training), school-enterprise cooperation practice platform (including cognitive practice, professional practice, employment practice, scientific research practice), graduation design and innovation research platform, etc. .

\section{A. Building practical innovation platform in school}

In the process of building an open professional laboratory, we should make full use of relevant industry needs, project development and other information from the industry to listen to the opinions and suggestions of enterprises on laboratory construction. In the construction of training base, we should make full use of the resources of enterprises. Signing agreements with enterprises can achieve common cooperation, mutual benefit and win-win results. It provides a good practice environment for training applied talents with strong practical ability.

\section{B. Strengthening school enterprise cooperation}

Through the channels of school enterprise cooperation, students are led to organize teaching in the field. With 5 or 6 students as a group, volunteer to play the role of project manager, system analyst, design engineer, test engineer, customer, can be familiar with the project development process, understand the role of responsibility [6]. Through this kind of company situational teaching method, students are familiar with the working environment and talent demand of the enterprise, and further develop the students' abilities of project analysis, design, development, testing and teamwork.

\section{Guide students to participate in various innovative activities}

Encourage students to independently create or participate in various innovative societies, practical competitions and innovative lectures. All kinds of innovative activities are organized for students in the whole school. According to the objective of cultivating practical innovation ability, we can organize and guide students to participate in various disciplines competition.

\section{Establishing An EFFECTIVE QUALITY AsSURANCE MECHANISM}

A. Improving the diversified assessment system aiming at cultivating students' practical and innovative ability.

Examination is an important part of testing students' learning effect. In order to further arouse and stimulate students' enthusiasm to participate in practical and innovative activities, a diversified assessment system aiming at cultivating students' practical and innovative ability can be adopted. Assess students by taking into account the comprehensive performance of pre-practice (quality of preview reports and random questions), practice (practical ability), and postpractice (practical reports). For different levels of practice and innovation activities, the emphasis of assessment should also be different, such as basic verification practice should focus on students' practical skills and results analysis; comprehensive design practice should focus on students' design ideas; research and innovation practice should focus on students' innovation.

\section{B. Establishing incentive system for practical innovation activities}

The school provides stable financial support to provide a basic guarantee for the practice of innovative activities [7]. In order to encourage students to participate in practical and innovative activities, different credits can be credited according to the degree of students' practical and innovative activities, and students can be encouraged to further develop practical and innovative activities. The students' practical and innovative activities are included in the comprehensive evaluation. Teachers who make outstanding contributions to the cultivation of students' practical and innovative abilities can be compensated, commended and rewarded.

\section{Strengthening supervision and management of practical teaching}

Each semester should organize a teaching Symposium attended by student representatives, teachers and teaching supervisors. Emphasis is laid on checking the links of practical and innovative teaching, grasping the real situation and existing problems of practical and innovative teaching in time, giving feedback to teachers and making suggestions.

\section{Building a contingent of teachers with practical and innovative ability}

Building a contingent of teachers with practical and innovative ability is the key support for training students' practical innovation ability. Teachers should be arranged to participate in the technical training of enterprises, keep abreast of the industry's dynamics and master the latest technology. It is necessary to organize teachers to participate in seminars nationwide and industry organizations and carry out academic exchanges with technical personnel. Through these measures, teachers can upgrade their professional knowledge, experience in project development and management, and make great progress in their innovative consciousness, practical ability and team spirit. 


\section{CONCLUSION}

The cultivation of practical ability of applied talents of electronic information specialty is a systematic project. Its cultivation mechanism is influenced by many factors. There is no universal model for reference. However, as long as we constantly explore and summarize in practice, we can form a practical ability training system that adapts to the characteristics of running schools and disciplines of Applied Colleges and universities, and can really enhance students' practical ability and cultivate applied talents of electronic information to meet the needs of society.

Acknowledgment: This work was supported by Ministry of education cooperation in production and education projects of China under Grant 201702065105.

\section{ACKNOWLEDGMENT}

F. Liu was born in Shijiazhuang, Hebei, China. She received the B.S. degree in Electronic Engineering from Hebei Normal University, Shijiazhuang, Hebei, China, in 2001, and the M.S. degree in Circuits and Systems from Yanshan University, Qinhuangdao, Hebei, China, in 2004. She is currently a Lecturer with the Institute of Antenna and Microwave Techniques, Tianjin University of Technology and Education, Tianjin, China. Her recent research interests include microwave circuit design, computational electromagnetics, etc.

\section{REFERENCES}

[1] Qin Long Yi, Song Danxia. Research on the Guarantee Mechanism of Applied Innovative Talents Training. Journal of Heilongjiang Education, no. 6, pp. 81-83, 2014. (In Chinese)

[2] Zhu Shuxin, Xu Huanliang, Li Xiaohui, et al. To Guide the Computer Majors' Practical and Innovative Ability with Excellent Education to Train. Journal of Agricultural Education in China, no. 3, pp. 12-15, 2014 (In Chinese)

[3] Ma Yongjie, Ma Yongjie, Peng Yulong. Cultivation and Practice of Innovative Ability of Engineering Students. Journal of Industrial and Information Education, no. 4, pp. 43-46, 2013. (In Chinese)

[4] Luo Wenguang, Hubo, Zeng Wenbo, et al. Research on SchoolEnterprise Cooperative Training Model of Applied Undergraduate Talents in Local Universities. Journal of Experimental Technology and Management, vol. 30, no. 3, pp. 15-18, 2013. (In Chinese)

[5] Yan Wei, Yuan Yunsong. Exploration and Practice of Cultivating College Students' Practical and Innovative Ability. Journal of China University Teaching, no. 9, pp. 78-80, 2012. (In Chinese)

[6] Liang Wenyao, Chen Wuxuan. Exploration on the Reform of Autonomous Experimental Teaching Based on the Cultivation of Innovative Ability. Journal of Laboratory Research and Exploration, vol. 31, no. 8, pp. 289-291, 2012. (In Chinese)

[7] Wu Shuqing. Deepening Higher Education Reform, Enhancing Innovative Ability and Promoting the Cultivation of Innovative Talents. Journal of Education Research, Tsinghua University, vol. 28, no. 5, pp. 1-7, 2008. (In Chinese) 